\title{
How Do Older Portuguese and Mexican Adults Experience Their Sexual Well-Being? A Cross-Cultural Qualitative Study
}

\author{
Sofia von Humboldt ${ }^{1}$ (D) Neyda Ma Mendoza-Ruvalcaba ${ }^{2}$. José Alberto Ribeiro-Gonçalves ${ }^{1}$. \\ Alejandro Chávez-Rodríguez ${ }^{2} \cdot$ Gail Low $^{3} \cdot$ Isabel Leal $^{1}$
}

Received: 4 December 2020 / Revised: 15 March 2021 / Accepted: 23 March 2021 / Published online: 27 August 2021

(c) The Author(s), under exclusive licence to Springer Science+Business Media, LLC, part of Springer Nature 2021

\begin{abstract}
Sexual well-being (SWB) refers to the subjective emotional and cognitive evaluation of the quality of the individual's sexuality. SWB plays a relevant role in quality of life and health promotion on old age and has cross-cultural implications. In addition to the scarcity of in-depth qualitative studies in this area and studies with cross-cultural samples, no studies have compared perceptions of SWB among Portuguese and Mexican older adults. The aim of this study was to comparatively analyze perspectives on SWB among older adults residing in Portugal and Mexico. Data were collected from 86 Portuguese and 80 Mexican community-dwelling participants aged 65 years and older, using a semi-structured interview protocol. Older adults were asked about factors that significantly contribute to their SWB. Sociodemographic data were also gathered. Content analysis was used to identify key themes. Eight themes were identified across both studied samples: eroticism, supportive relationship, positive self-concept, health and self-care, romance, active life, tenderness and care, and no pain and no pregnancy restrictions. Eroticism was most pertinent to Portuguese participants (31.4\%). Health and self-care was most frequently reported by Mexican participants $(26.5 \%)$. The findings of this study indicate that SWB is strongly influenced by sociocultural and psychosocial values. Cross-cultural comparisons between older Portuguese and Mexican people provide a broader understanding of SWB in older age and suggest a scenario for future culture-adapted interventions and comprehensive policies.
\end{abstract}

Keywords Cross-cultural $\cdot$ Older adults $\cdot$ Qualitative research $\cdot$ Sexual well-being

\section{Introduction}

Population aging has become a global reality and is a growing trend associated with rising average life expectancy (World Health Organization [WHO], 2015). Indeed, by the year 2050, the older adult population is estimated to be two billion people (United Nations [UN], 2015; WHO, 2015). The impact of this growth will vary among countries. Portugal is currently among the five oldest countries in the world and, in 2050, approximately $40 \%$ of the population will be 60 and older (UN, 2015). Mexico

Sofia von Humboldt

sofia.humboldt@gmail.com

1 William James Research Center, ISPA-Instituto Universitário, Rua Jardim do Tabaco, 34, 1149-041 Lisbon, Portugal

2 Health Sciences Division, University of Guadalajara CUTONALA, Guadalajara, Jalisco, Mexico

3 Faculty of Nursing, University of Alberta, Edmonton, AB, Canada is currently undergoing an abrupt demographic aging and, in $2050,23 \%$ of its population is expected to be aged 60 or over (Angel et al., 2016).

Research has reiterated the need to manage significant demographic changes, particularly in what concerns health and quality of life, since older adults may have more and better health while living longer (European Commission [EC], 2017; UN, 2015; WHO, 2015). For the period 2020/2030, the WHO aims to implement a health model focused on the promotion of older adult well-being, with less importance given to the disease-centered model (WHO, 2015). Sexual well-being (SWB) and health have gained increasing importance, evidencing their relevant role toward well-being, quality of life, and disease prevention and health promotion in old age (Kleinstäuber, 2017; WHO, 2010).

SWB is an umbrella concept that refers to the subjective emotional and cognitive evaluation of the quality of the individual's sexuality (Santos-Iglesias et al., 2016; Štulhofer et al., 2019). SWB integrates a set of dimensions, predominantly positive, that vary according to the conceptual model. SWB is frequently defined in an eudemonic way, focused on sexual functioning, or 
in anhedonic way, focused on subjective pleasure experiences (Graf \& Patrick, 2014; Kleinstäuber, 2017; Santos-Iglesias et al., 2016; Štulhofer et al., 2019; von Humboldt et al., 2015, 2020, 2021). One of the best-known definitions of SWB contains dimensions such as physical pleasure, satisfaction with sexual function, emotional pleasure and importance of sex (Laumann et al., 2006; Rosen \& Bachmann, 2008). However, recent literature suggests that because of its specificities, SWB in old age has to be characterized in a partially different way, especially since several studies indicate that older adults seem to value care, intimacy and physical proximity more than sexual activity itself (Fileborn et al., 2018; Freak-Poli et al., 2017; Štulhofer et al., 2020).

Several authors have been working to determine the best conceptualization of SWB, considering the construct more broadly, and testing it in cross-cultural samples, given that SWB can be perceived differently in different cultures (Laumann et al., 2006; Štulhofer et al., 2019; von Humboldt et al., 2018). These studies suggest that SWB concerns physical attraction, sexual desire, importance of sexual activity, emotional satisfaction and intimacy with a partner (von Humboldt et al., 2018), sexual intimacy, sexual satisfaction, cuddling frequency, perceived sexual compatibility and absence of sexual function distress (Štulhofer et al., 2019). Cross-cultural data on older adult SWB has been difficult to obtain, especially intercontinental data (e.g., comparison between American and European older adults), but would be valuable to study perceptual differences across cultures (FreakPoli et al., 2017; Kleinstäuber, 2017; Štulhofer et al., 2019; von Humboldt et al., 2018).

A previous study comparing 29 countries across five continents suggests that, particularly in Western European countries, more than $60 \%$ of the older adults report high levels of SWB. This study used a Mexican sample, but not a Portuguese sample. In addition, to date, no studies have compared perceptions of SWB among Portuguese and Mexican older adults (Laumann et al., 2006). This lack in-depth qualitative studies hinders comparisons of factors that can influence SWB in older adults (Schaller et al., 2018; Træen, et al., 2017a, 2017b). A number of quantitative studies have evaluated older adult SWB, although few included cross-cultural samples. These studies indicated that higher levels of SWB may be associated with lower mortality rates, lower levels of stress and fewer sexual dysfunctions, higher relational satisfaction, higher sexual desire, better cognitive performance, and better cardiovascular health (Bouman et al., 2006; Brody, 2010; Golub et al., 2011; Hinchliff et al., 2017; Kleinstäuber, 2017; Santos-Iglesias et al., 2016; von Humboldt et al., 2018).

Studies on SWB can be an important resource for interventions to promote health, functional capacity, well-being, and quality of life in old age (Bell et al., 2016; Syme et al., 2018). Similarly, SWB studies, particularly qualitative ones, may be key for promoting specific intervention programs in the field of public health (e.g., programs for sexually transmitted infections; Bouman et al., 2006; Fileborn et al., 2018; Golub et al., 2011).
Moreover, in addition to the strong influence of sociocultural and moral factors on the SWB of older adults, there are several inconsistencies in the studies of sexuality in old age (Bell et al., 2016; Træen et al., 2019). These studies, significantly scarce in number, focus predominantly on negative and dysfunctional sexual aspects from a biomedical perspective and mostly in Europe or America (DeLamater, 2012; Peixoto \& Nobre, 2015; SantosIglesias et al., 2016). There is a need for cross-cultural qualitative studies (Bell et al., 2016), allowing a wider exploration of the SWB indicators, and comparisons and applications in crosscultural interventions. All such work would afford a conceptually cohesive definition of SWB (DeLamater, 2012; Štulhofer et al., 2019; von Humboldt et al., 2018). This study sought comparisons of what contributes to SWB from the perspective of older people living in Portugal and Mexico.

\section{Method}

\section{Participants}

We shared our study objectives with 166 community-dwelling older people by telephone or in person (e.g., for those with sensorial difficulties). Older Portuguese people were contacted throughout February and April 2018. Older Mexican people were contacted between June 1 and August 7, 2018. Eligibility included two criteria: cognitive level (above the MMSE cut-off level) and age over 65 years old. A nonprobabilistic convenience sampling was used. The Portuguese sample included 86participants with an average age of 71.8 years $(\mathrm{SD}=3.6)$. Approximately $45 \%$ had at least four years of schooling, $65 \%$ were women, almost a third (26\%) lived alone, and nearly $70 \%$ had a partner. Mexican participants $(n=80)$ were, on average, 71.7 years old $(\mathrm{SD}=6.14), 65 \%$ were women, $46.1 \%$ completed primary school and $3.8 \%$ were illiterate, $40 \%$ lived alone, and nearly half were married or in a relationship (48.8\%). None of the participants had a history of psychiatric illness or drug abuse, which might compromise cognitive function. No monetary compensation was offered to participants. See Table 1.

Consenting older Portuguese and Mexican adults took part in semi-structured interviews, with an average duration of $40 \mathrm{~min}$. The interviews were audio recorded and fully transcribed, and later subjected to content analysis (Bardin, 1977). The semistructured interview focused on older adult perceptions of what contributes to their "SWB." For this purpose, participants were asked the following question: "I would like to understand what, from your point of view, contributes to your sexual well-being in this phase of your life?" In order to standardize the data collection process, in Mexico and Portugal, all interviewers had a short guide with the semi-structured interview structure and received prior training to develop these interviews. For use in the Mexican study, the original guide for the semi-structured interview, in 
Table 1 Sample sociodemographic and health characteristics

\begin{tabular}{|c|c|c|c|}
\hline Characteristics & Portuguese $(n=86)$ & Mexican $(n=80)$ & Total $(n=166)$ \\
\hline Age, mean \pm SD & $71.8 \pm 3.6$ & $71.28 \pm 6.41$ & $71.54 \pm 5.0$ \\
\hline \multicolumn{4}{|l|}{ Gender, $n(\%)$} \\
\hline Women & $56(65.0)$ & $52(65.0)$ & $108(65.0)$ \\
\hline Men & $30(35.0)$ & $28(35.0)$ & $58(35.0)$ \\
\hline \multicolumn{4}{|l|}{ Living status, $n(\%)$} \\
\hline Alone & $22(26.1)$ & $32(40.0)$ & $54(32.6)$ \\
\hline With sons & $3(2.9)$ & $22(27.5)$ & $25(15.0)$ \\
\hline With a partner & $61(71.0)$ & $26(32.5)$ & $87(52.4)$ \\
\hline \multicolumn{4}{|l|}{ Education $n(\%)$} \\
\hline Illiterate & $0(0.0)$ & $3(3.8)$ & $3(0.1)$ \\
\hline Primary school & $30(34.2)$ & $37(46.1)$ & $67(40.2)$ \\
\hline Middle school & $25(29.4)$ & $24(30.1)$ & $49(29.5)$ \\
\hline$\geq$ High school & $31(36.4)$ & $16(20.0)$ & $47(28.2)$ \\
\hline \multicolumn{4}{|l|}{ Marital status $n(\%)$} \\
\hline Married or cohabiting & $59(69.1)$ & $39(48.8)$ & $98(59.0)$ \\
\hline $\begin{array}{l}\text { Having a spouse or other } \\
\text { intimate relationship }\end{array}$ & $27(30.9)$ & $41(51.2)$ & $68(41.0)$ \\
\hline \multicolumn{4}{|l|}{ Professional status $n(\%)$} \\
\hline Active & $18(21.3)$ & $24(30.0)$ & $42(25.3)$ \\
\hline Inactive & $68(78.7)$ & $56(70.0)$ & $124(74.7)$ \\
\hline \multicolumn{4}{|l|}{ Family annual income $n(\%)$} \\
\hline$\leq 25,000 €$ & $34(40.1)$ & $80(100)$ & $114(68.7)$ \\
\hline$>25,000 €$ & $52(59.9)$ & $0(0)$ & $52(31.3)$ \\
\hline \multicolumn{4}{|l|}{ Perceived health $n(\%)$} \\
\hline Good & $56(65.1)$ & $67(83.8)$ & $123(74.1)$ \\
\hline Poor & $30(20.9)$ & $13(16.3)$ & $43(25.9)$ \\
\hline
\end{tabular}

Portuguese, was translated into Spanish by experts on gerontology and then verified with the back-translation method.

\section{Data Analysis}

Content analysis followed methods outlined by Bardin (1977) and Neuendorf (2002), resulting in an adapted step-by-step process (see Fig. 1). After data collection, the first step was to build a codebook. The coding process began by conceptualizing and categorizing data into relevant dimensions for further analysis. Then, a number code was attributed to each category, giving rise to a codebook (Sampaio \& Lycarião, 2018; Singh, 2007). The coding scheme followed important rules to allow replicability and reliability (e.g., mutually exclusive codes, applied consistently, with comprehensive coding formats for each item). This coding system identified at least three aspects of text content: frequency, direction and intensity (Bengtsson, 2016; Elo et al.,
2014; Erlingsson \& Brysiewicz, 2017; Neuman, 2011; Sampaio \& Lycarião, 2018). Two psychologists coded exactly the same materials independently (Sampaio \& Lycarião, 2018) and high inter-coder agreement was observed ( $k$ Portuguese $=0.87$, $p<.01 ;$ Mexican $=0.83, p<.01)$.

Regarding consensus of the emerging themes and sub-themes, the previous coding process was afterwards organized through a categorization process, by regrouping according to dimensions/ themes established with clear criteria, well defined previously and consensually by the coders. This process involved two steps: (1) Inventory: isolation of the elements, and (2) Classification: distribution of the elements by seeking or imposing a certain organization on the content (Bardin, 1977; Sampaio \& Lycarião, 2018). This categorization process was achieved through an a posteriori approach, with no previous category system, but as the result of the analogical and progressive classification of the elements (Bardin, 1977; Vala, 1989). A set of general classification principles were applied in order to constitute a categorization of 

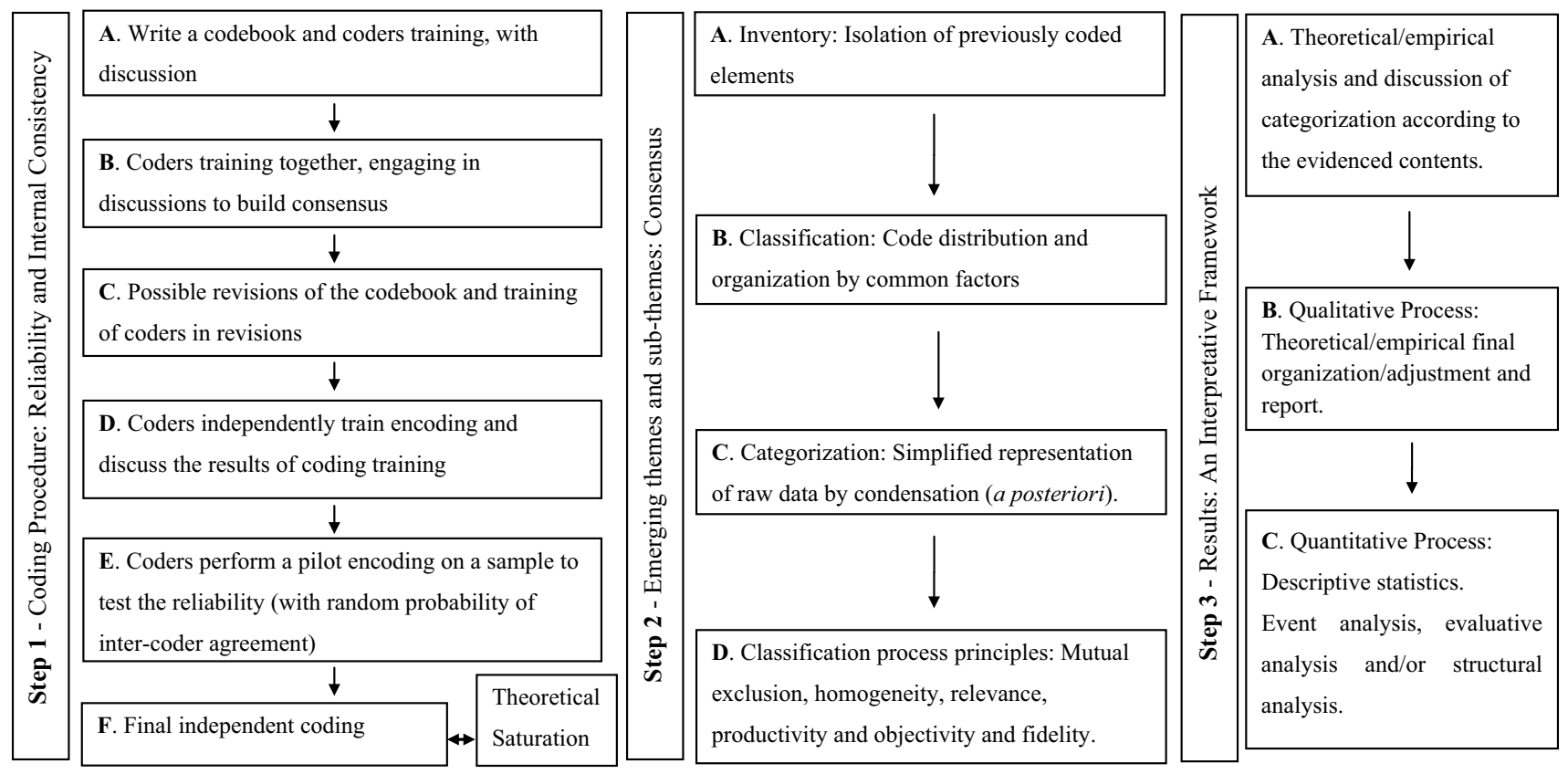

Fig. 1 Adapted step-by-step process of content analysis

consensual and robust themes (Sampaio \& Lycarião, 2018; Vala, 1989). Such principles included: mutual exclusion (each element can exist only in one category); homogeneity (a single classification principle must prevail in the organization within a single set of categories); relevance (categories belong to the defined theoretical framework and reflect the research intentions); objectivity and fidelity (categorized variables must be clearly defined and the parts of the same material must be similarly coded, specifying the indexes that determine classification of an element into a category); and productivity (the categories provide fertile results, inferences, new hypotheses, and exact data; Bardin, 1977; Vala, 1989).

Finally, regarding the elaboration of an interpretative framework of the results, the descriptive nature was fundamental toward the analysis and theoretical-empirical discussion of the resulting themes. These qualitative elaborations were rightfully oriented toward the exploration, discussion and analysis of the content that emerged during the process. An additional informative quantification process occurred through the calculation of frequencies, percentages, mean, medians, averages, and direction (Bengtsson, 2016; Elo et al., 2014; Erlingsson \& Brysiewicz, 2017).

\section{Results}

We analyzed eight non-mutually exclusive themes that represented the cultural diversity of narratives expressed by older Portuguese and Mexican people: eroticism, supportive relationship, positive self-concept, health and self-care, romance, active life, tenderness and care, and no pain and no pregnancy restrictions. It is remarkable that we found no differences in thematic coding in the responses across both cultural groups. Themes are inclusive, unless otherwise indicated. Although participants did not explicitly verbalize the denomination "sexual well-being", their narratives were all related to this construct.

\section{Theme 1: Eroticism}

Eroticism was the most reported theme by 27 Portuguese and 12 Mexican participants. Indeed, an important factor in sexual expression in late life is eroticism. Participants expressed that feeling attractive, experimenting with sexual desire and pleasure, as well as being sexually satisfied contributes to SWB. As Joao indicated, "eroticism is natural and should be treated in this way" (Joao, 73 years old). People may believe that as we get older, eroticism disappears. In this regard, Mariana verbalized that "people are surprised that we are still erotic" and added, "I really enjoy our intimate games and with online shopping, we feel that our creativity has been expanded" (Mariana, 67 years old). Antonio verbalized that "what is important is to feel pleasure at the moment when you are hot" (Antonio, 84 years old). Participants 
also indicated that having satisfying intercourse and trying different sexual positions are important for SWB. In this theme, Juan (74 years old), verbalized that “....without that [eroticism], a person is nothing...", while Maria (62 years old) reported that "the number of times one has intercourse is also important."

\section{Theme 2: Supportive Relationship}

Eighteen Portuguese participants and 13 Mexican participants indicated that a supportive relationship is important for their SWB. Having a supportive relationship was the second most reported theme by participants in general. Older adults believe in the importance of a supportive relationship, particularly a supportive relationship with a significant other. Susana said that "Being married is more than having a ring on your finger. That ring represents our relationship and how we will support each other, in the good and bad moments" (Susana, 65 years old). A supportive relationship is important in late life and, as Ana indicated, "Having a partner who listens to us, supports us and helps us in decisions, influences our intimacy" (Ana, 69 years old). Mutual assistance is also an important factor for the elderly. Ana indicated that, "my partner has some breathing problems, so we both decided to enroll in yoga so that we can exercise. Decisions like these, in a relationship, will influence our sexual expression" (Ana, 69 years old). Moreover, "having a partner and getting along is important for me" expressed Julia (67 years old), while Daniel narrated that "having a stable marriage" was important for his SWB (Daniel, 67 years old). Older adults verbalized the relevance of being part of a couple, of having a friend and a significant other as a companion. Some participants reported that relationships with other family members are also important: María (76 years old) expressed that "having good relationships with other people, with family and children" contributes to SWB.

\section{Theme 3: Positive Self-Concept}

Participants considered that having a positive self-concept was important for SWB $(n=27)$. This theme was mostly reported by Portuguese participants $(n=24)$. Self-concept refers to the perspective one has of oneself and one's abilities. Participants mentioned having a positive self-concept and perceiving a person's attributes come to life through feeling attractive and enjoying life. Diana reported that "sometimes people make us believe that we are worthless, just because we are old; obviously that will influence the way I relate to others, whether I feel well about myself" (Diana, 84 years old). A positive perception was frequently highlighted by participants: "How can I have a relationship with someone if I think I do not have a good image of myself and about my partner?" asked Filipa (71 years old). Jim added: "having a positive image of oneself is essential to help seduce a person. There was a phase when my wife was feeling ugly, so I had to show her that I only had eyes for her. From that point, every day I told her that she was the most beautiful woman in the world. It didn't take a too long to change her mind" (Jim, 76 years old). Personality traits and mood were also related to feeling good about oneself and considered contributors to SWB: "He is always in a good mood. It's difficult to say no to him" (Coco, 76 years old).

\section{Theme 4: Health and Self-Care}

Twenty-two Mexican older adults and four Portuguese referred ideas related health and self-care to their SWB (e.g., good nutrition, sleep, hygiene and health). Victor (72 years old) verbalized "Being healthy, eating well and taking vitamins is important for me. When I feel well, I also feel more available for sex and I actually think more often about having sex." Maria added that "sleeping well, keeping myself clean and groomed was important for me and my sexual drive." Feelings of relaxation and tranquility were also referred in relation to this theme. Ana ( 65 years old) indicated that "being relaxed and having no problems" contributed for her SWB. Carmen added that "for me, my tranquility the most important" (Carmen, 84 years old). Another sub-theme referred to by participants was the absence of disease and pain. Luis indicated that "there was a time when I was not well. Now I feel healthy and that reflects into my sexuality. I challenged my life by surviving cancer and now I can have a normal sex life" (Luis, 67 years old).

\section{Theme 5: Romance}

Sixteen Portuguese and five Mexican participants referred to romance. Romance was described as a state that should persist in old age and especially after a long period of life in common with a loved one, after even after conquering the loved one. "I love the fact that, after so many years, he continues to give me flowers and gifts once in a while! I love this romantic side of him!" exclaimed Susana (81 years old). Being romantic is important for older adults. There were reports of emotional expressions of romance and love in this study. "For me, feeling loved is very important" expressed Graciela ( 73 years old). Angela explained that "a girl's biggest dream is to be treated like a queen and I can say that I am treated like one! I have a real lover by my side!" (Angela, 76 years old). Some participants indicated the importance of addressing the romantic needs of a loved one. Gabriel indicated that "Every day, she shows that she loves me; sometimes, with a kiss early in the morning, sometimes with dinner at night and of course these small gestures make a difference in our sex life" (Gabriel, 71 years old).

\section{Theme 6: Active Life}

Having an active life was verbalized by nine Mexican and six Portuguese participants. Physical activity, being busy and informal exercise were identified as relevant for preserving SWB in old 
age and promoting physical and mental health in older age. Gina indicated that "having an active life is important for being flexible in bed, which is why I signed up for gymnastics lessons" (Gina, 67 years old). These older adults highlighted that feeling active and alive was relevant for their SWB. "Every day, my wife and I go for a walk in the morning. We spend time together and we are still contributing to our health. And in the evening we have more exercise in our bedroom", verbalized Carl (68 years old). Some participants indicated that being active does not mean practicing exercise in the gym, but also performing daily activities, such as cleaning the house. "I like to be busy. I always find things to do at home. And then I feel active in every sense of life" (Sandra, 71 years old). Lola verbalized that "for me, having activities and keeping myself busy with something is important" (Lola, 71 years old). Celina ( 73 years old) and Margarita ( 85 years old) also verbalized that "having a very active life, getting from one side to another" was a contributor to their SWB.

\section{Theme 7: Tenderness and Care}

Eleven participants indicated tenderness and care was part-andparcel of their SWB. Tenderness and care were mostly reported by Portuguese participants $(n=9)$. Two Mexican participants also verbalized this theme. "Being in love is not just a luxury for the youngest. Older adults also need warmth and affection. Even more, they fight loneliness. I am not alone. I have a companion that loves me and that is why I am happy!" (Olga, 68 years old). Philip added that "I miss her, she made me smile with her jokes and now I'm alone. She took care of me and cared about me. I still love her so much" (Phillip, 71 years old). Finally, Sonia indicated that "I like to be touched and massaged and I love when he asks what I most like to do in bed. He complements me in all the senses" (Sonia, 82 years old).

\section{Theme 8: No Pain and No Pregnancy Restrictions}

This theme was exclusively indicated by Portuguese participants $(n=10)$ and all such participants were women. The freedom of not having to worry about a possible pregnancy and the fact that sexual intercourse was free of pain was important. Celia indicated that "I am so lucky. Menopause is over and now I can concentrate on enjoying sex. I don't feel pain anymore and finally I am free of fear from getting pregnant. How good is that?" Carolina added that "For 40 years I worried about getting pregnant. Now I feel free as a bird. Younger women don't know what they are missing. I love my new life since I feel like a lover. I don't want to miss anything good that life may offer me" (Carolina, 72 years old).

\section{Discussion}

Analysis of participant interviews generated eight non-mutually exclusive themes related to the older adult perspectives on SWB: eroticism, supportive relationship, positive self-concept, health and self-care, romance, active life, tenderness and care, and no pain and no pregnancy restrictions. With the exception of the very last theme, all were indicated by men and women from both samples, but cultural differences manifested through different frequencies. For example, eroticism, the main theme in this study, was most pertinent to Portuguese participants.

Although the body gets older and diverges from social patterns of attractiveness, eroticism can and should continue to exist in old age among men and women, by sharing intimate experiences or through games of seduction (Katz, 2010; Træen, et al., 2017a, 2017b; Watson et al., 2016). Likewise, there is high variability in the internalization of the importance of physical attractiveness according to ethnicity, educational level and sexual orientation (Clarke, 2002). Beauty social stereotypes accentuate the loss of eroticism in elderly men and women by promoting only slim, young and athletic bodies as the ideal erotic body (Clarke, 2002; Træen et al., 2017a). This, in turn, has a marked impact on how older people live and express their sexuality (DeLamater \& Moorman, 2007). Thus, eroticism can be an important resource in the daily life of older adults, promoting self-esteem, general wellbeing, self-perception of competence, and is a good indicator of SWB (DeLamater, 2012; DeLamater \& Moorman, 2007; Watson et al., 2016).

A supportive relationship was the second most reported theme, indicated mostly by Portuguese participants. The social support network is one of the most important variables for the well-being of older adults. Over time, older people's support networks shrink, but they tend to increase investments in quality relationships that they wish to maintain. Therefore, instrumental and emotional support is essential for quality of life in old age (Hillman, 2012; Katz, 2010; Reinhardt et al., 2006; von Humboldt \& Leal, 2015; von Humboldt et al., 2013b, 2014a, 2014b). Sometimes, when families impose resistance to the sexual practices of older adults, friendships and/or peers can provide important support for expressions of sexuality and contribute to older adult SWB (Hillman, 2012; Sinković \& Towler, 2018). Family support, often provided by a spouse or adult children, may be an important resource for older adults in the end of their lifespan, because generally a few family members are the close, trusted and relevant confidantes (Merz et al., 2009; von Humboldt \& Leal, 2014a, 2014b; von Humboldt et al., 2014a, 2014b, 2015). Although seemingly less important than family support, support provided by non-kin network members has been found to 
generally increase well-being and to simultaneously bring other positive outcomes in later life (Merz \& Huxhold, 2010; Unsar et al., 2016).

Having a positive self-concept was mostly reported by Portuguese participants. Engagement in sexual practices is closely associated with sexual self-concept, particularly the initiative to engage in sexual behavior (Cotter \& Gonzalez, 2009; DeLamater, 2012). But general self-concept also influences one's ability to perceive oneself as capable and reliable, and to consider oneself as someone with more/less aptness and aptitude for particular activities, including the expression of sexuality (Cotter \& Gonzalez, 2009; DeLamater \& Moorman, 2007; Hillman, 2012). Physical health, health resources, relationship status, and family support are the variables most associated with self-concept. Living independently, being healthy, feeling competent, and having a partner are generally identified as relevant precursors of positive selfconcept in older age (Carneiro et al., 2019; DeLamater, 2012; Ferreira-Valente et al., 2019; Pinquart \& Sörensen, 2001; Ribeiro-Gonçalves et al., 2021). However, there seem to be some variations according to gender. For example, men's self-concept seems to be more connected with their careers, whereas social network events are important for women (Pinquart \& Sörensen, 2001).

For Mexican participants, health and self-care was the most frequent theme related to SWB. Physical activities (e.g., structured and non-structured) and good health have been reported as significant predictors of persistent sexual interest and enjoyment in older adults in four European countries (Træen et al. 2019). Conversely, poorer self-rated health has been associated with reduced frequency of sexual intercourse in men and women (Fischer et al., 2021). Sexual activity, quality of sexual life, and interest in sex were positively associated with health in later life, specifically health was strongly associated with having a partner, particularly for older women (Lindau \& Gavrilova, 2010). Research on health conditions affecting sexual health covers a variety of conditions (e.g., diabetes, menopause, incontinence, dementia, traumatic brain injury, general fatigue, prostatic hyperplasia), revealing the importance of overall health for sexual functioning in old age. However, most men and women indicate that psychological as opposed to physiological factors affect their sense of well-being, with the relationship context determining whether sexual problems have an impact on wellbeing (Sinković $\&$ Towler, 2018). Moreover, Mexican older people seem to have less resources than Portuguese older adults (e.g., significantly lower annual income), which may have influenced the reporting of central indicators of the SWB, such as mental and physical health, and self-care, in contrast to the Portuguese older adults, for whom dimensions like eroticism were relevant.

Romance was deemed most important for SWB among Portuguese participants. Romantic expression in aging depends largely on how romantic and sexual expression happened throughout life (DeLamater, 2012). This expression implies a positive perspective of aging and is hindered by factors such as low sexual self-concept, loss of a partner and negative sexual experiences (DeLamater \& Moorman, 2007; Smith et al., 2019). The social perception of older adults as passive agents-without sexuality, libido and romanticism to develop an affective-sexual relationship-removes power and social autonomy from sexual expression (DeLamater, 2012; Træen, et al., 2017a, 2017b). These forms of invisibility and delimitation are socially constructed and define the social and cultural image of old age based on loss, rejection, and illness (Santos-Amaya \& Carmona-Valdés, 2016). Romantic and sexual expression can differ by biological sex, but there is also a psychosocial double standard concerning male and female older adult sexuality. Older women's participation in sexual activities is viewed as evil and unnatural, while men's participation in sex is viewed as silly or humorous (DeLamater \& Moorman, 2007; Hillman, 2012).

Having an active life was mostly frequently alluded to by Mexican participants. An active, physical, cognitive and affective aging is associated with lower levels of sedentarism, which decreases the likelihood of functional losses and subsequently influences sexual expression and sexual behavior (Hillman, 2012; Raguso et al., 2006). Maintaining frequent activity increases the sense of usefulness and empowerment, giving greater security in various areas of daily life, including sexuality (Foley, 2015; Mendoza-Ruvalcaba \& Fernández-Ballesteros, 2016; Rheaume \& Mitty, 2008). However, there are often important obstacles that make it difficult for older adults to live an active life (e.g., chronic diseases). Regardless of health difficulties, self-perceived health appears to effect SWB. Among older men and women who rate their health as excellent, almost half reported having sex weekly and only $14 \%$ who rated their health as "poor" were doing so (Hillman, 2012). Moreover, sexual expression is very much associated with energy, vitality and feeling alive (Mendoza-Ruvalcaba \& Fernández-Ballesteros, 2016).

Tenderness and care was most frequently mentioned by Portuguese participants. SWB in older people seems to be less associated with genitality and more with care, attention, tenderness, hugs, kisses, and other affectionate behaviors and attitudes (DeLamater, 2012). Engagement in physical tenderness or having frequent sexual activity was linked to greater social support, healthy behaviors, younger ages, and better physical and psychological health (Mahieu \& Gastmans, 2015). However, as many older people may lose their partners, engaging in sexual play, caring, affection, care and other intimate behaviors may be constrained, influencing their SWB (DeLamater, 2012; Hillman, 2012). In older age, a sexual partner's availability can reflect gender differences in sexual activity and physical tenderness; however, the possibility of sexual activity and physical tenderness outside a committed relationship is possible, and perhaps more so for men (Freak-Polia et al., 2018; Hillman, 2012). In this sense, the involvement in tenderness and affection behaviors in older adults should be accepted as an expression of sexuality, rather than a restriction (DeLamater, 2012; Hillman, 2012). 
Finally, no pain and no pregnancy restrictions were indicated by Portuguese women. The Western model of sexual expression still largely centers around reproduction (Træen et al., 2017a), a function limited or lost in older age (Pearce, Thøgersen-Ntoumani, \& Duda, 2013). In this sense, there may be a clear decrease in involvement in sexual activity at these ages, but there may also be less concern about procreation and a more free and uninhibited involvement in sexual behavior (DeLamater, 2012; Hillman, 2012; Minichiello et al., 2012). This lack of concern may also be a risk factor, as it may lead to disregard for health care (e.g., contraceptive barrier methods), thus increasing the likelihood of diseases, such as sexually transmitted infections (Minichiello et al., 2012). This trend may also lead to a wider transmission of this type of disease, as these risk behaviors may be more frequent in older adult population (DeLamater \& Moorman, 2007; Minichiello et al., 2012). This reality underlines the importance of sexual psychoeducation in older adults to promote sexual health and prevent sexually transmitted infections (DeLamater, 2012).

Cultural differences in this study manifested through differing frequencies for themes. Eroticism, a positive self-concept, and a supportive relationship were most relevant for Portuguese participants' SWB. For Portuguese older adults, health and self-care was the least important theme. Among Mexican participants, health and self-care was the most frequent theme. Mexican participants also indicated that a supportive relationship was important for their SWB, while their least important theme was positive self-concept. The absence of pain and pregnancy restrictions was pertinent for Portuguese women alone. Although cultural studies are scarce, some studies (e.g., European and North American) reveal relevant and diverse results (Fischer et al., 2021; Laumann et al., 2006). Sexuality, and particularly SWB, is a construct strongly influenced by sociocultural and psychosocial values. Thus, due to the mutability of how SWB manifests in different cultures and in the older population, studies like the present one represent important sources of useful information for ethnographic interventions to enhance sexuality (Hinchliff et al., 2017; Træen et al., 2017a, 2017b). The findings in these studies represent a diversity of experiences and a very rich source for new research questions (von Humboldt \& Leal, 2014a, 2014b, 2015; von Humboldt et al., 2013a, 2014a, 2014b, 2015, 2018). Additionally, cross-cultural and qualitative studies clarify inconsistencies that occur among monocultural studies (Fischer et al., 2021). Bell et al. (2016) point out that cross-cultural studies are needed to clarify the methodological difficulties and inconsistencies found in several studies addressing sexuality in older adults (see also Traeen et al., 2019).

The present study has a number of limitations that need to be addressed. The Mexican sample did not include participants who self-identify as gay, lesbian, bisexual, transgendered, or other. Therefore, gender identity comparisons were not possible. Factors that contribute to SWB within the context of gender identity warrants empirical attention. In addition, participants' responses may have been biased due to social expectations. Another limitation is that although SWB was considered as a component of general satisfaction with life and well-being (Træen \& Villar, 2020), some participants felt that SWB was not important or of little interest to them. Studies report that older adults engage in sexual activity less frequently when compared to younger cohorts, and older sexually active women and men report lower sexual function compared to younger cohorts (Mitchell et al., 2013). Furthermore, health conditions, religion and marital status have been related to indifference toward sexual activities in later life (Sinković \& Towler, 2018; Torres \& Rodríguez-Martín, 2019).

Notwithstanding the above limitations, this cross-cultural qualitative study fills a gap in the Gerontological literature. Several studies have emphasized the need for in-depth qualitative studies that address the sexual health of the older population; studies on SWB are scarce (Hinchliff et al., 2017). So too are cross-cultural studies on sexual health (Fischer et al., 2021; Laumann et al., 2006). This makes simultaneously qualitative and cross-cultural studies scarcer. Nonetheless such studies permit a more in-depth assessment and identification of positive and negative health dimensions in various contexts, helping to identify patterns of variables that may influence SWB, in addition to allowing SWB to be characterized in a more complete and comprehensive way (Štulhofer et al., 2020; von Humboldt et al., 2018). The collection of more complete and representative data on diverse ways of living and expression of SWB also represents an important contribution to the implementation and adjustment of international policies on sexual health in older adults, which is becoming increasingly important (Bell et al., 2016; von Humboldt et al., 2018). Hence, the present cross-cultural qualitative study represents an important step toward consolidating and characterizing the concept of SWB in old age, reducing the empirical gap in comparative research of different cultures on SWB in older adults, and leading to interventions and comprehensive policies for large geographical areas.

Author Contributions SVH contributed to study concept and design, analysis and interpretation of data, recruitment of subjects, and preparation of manuscript; NMR contributed to analysis and interpretation of data, recruitment of subjects, and preparation of manuscript; JARG was involved in preparation of manuscript; ACR contributed to analysis and interpretation of data, and recruitment of subjects; GL contributed to study concept and design and interpretation of data; and IL was involved in study concept and design, and interpretation of data. All authors read and approved the final manuscript.

Funding This work was supported by the Portuguese Foundation for Science and Technology, under Grant (No. SFRH/BPD/116114/2016).

\section{Declarations}


Ethical approval The ethics committee and review board of the William James Center for Research, the ISPA-Instituto Universitário, the Portuguese Foundation for Science and Technology, and the Research and Ethics Committee from the Health Science Division at the Universitary Center of Tonala at University of Guadalajara approved this study.

Conflict of interest The authors report no conflicts of interest. The authors alone are responsible for the content and writing of the paper.

\section{References}

Angel, J. L., Vega, W., \& López-Ortega, M. (2016). Aging in Mexico: Population trends and emerging issues. The Gerontologist, 57(2), 153-162. https://doi.org/10.1093/geront/gnw136.

Bardin, L. (1977). Análise de conteúdo $1^{e d}$ [Content analysis 1st ed.]. Lisboa: Edições 70.

Bell, S., Reissing, E. D., Henry, L. A., \& VanZuylen, H. (2016). Sexual activity after 60: A systematic review of associated factors. Sexual Medicine Reviews, 5(1), 52-80. https://doi.org/10.1016/j.sxmr. 2016.03.001.

Bengtsson, M. (2016). How to plan and perform a qualitative study using content analysis. NursingPlus Open, 2, 8-14. https://doi. org/10.1016/j.npls.2016.01.001.

Bouman, W. P., Arcelus, J., \& Benbow, S. M. (2006). Nottingham Study of Sexuality and Ageing (NoSSA I). Attitudes regarding sexuality and older people: A review of literature. Sexual and Relationship Therapy, 21(2), 149-161. https://doi.org/10.1080/1468199060 0618879

Brody, S. (2010). The relative health benefits of different sexual activities. Journal of Sexual Medicine, 7(4), 1336-1361. https://doi.org/ 10.1111/j.1743-6109.2009.01677.x.

Carneiro, F. A., Costa, P. A., \& Leal, I. (2019). Psychometric analysis of the Portuguese version of the Family Sense of Coherence. Psicologia, Saúde \& Doenças, 20(3), 838-858. https://doi.org/10. $15309 / 19$ psd200322

Clarke, L. C. H. (2002). Beauty in later life: Older women's perceptions of physical attractiveness. Canadian Journal on Aging, 21, 429-442. https://doi.org/10.1017/S0714980800001744.

Cotter, V. T., \& Gonzalez, E. W. (2009). Self-concept in older adults: An integrative review of empirical literature. Holistic Nursing Practice, 23(6), 335-348. https://doi.org/10.1097/hnp.0b013 e3181bf37ea.

DeLamater, J. (2012). Sexual expression in later life: A review and synthesis. Journal of Sex Research, 49(2-3), 125-141. https://doi. org/10.1080/00224499.2011.603168.

DeLamater, J., \& Moorman, S. M. (2007). Sexual behavior in later life. Journal of Aging and Health, 19(5), 921-945. https://doi.org/10. 1177/0898264307308342.

Elo, S., Kääriäinen, M., Kanste, O., Pölkki, T., Utriainen, K., \& Kyngäs, H. (2014). Qualitative content analysis. SAGE Open, 4, 1-10. https://doi.org/10.1177/2158244014522633.

Erlingsson, C., \& Brysiewicz, P. (2017). A hands-on guide to doing content analysis. African Journal of Emergency Medicine, 7(3), 93-99. https://doi.org/10.1016/j.afjem.2017.08.001.

European Commission (EC). (2017). The 2018 Ageing Report: Underlying assumptions \& projection methodologies (1st ed.). Brussels, Belgium: Author.

Ferreira-Valente, A., Sharma, S., Torres, S., Smothers, Z., Pais-Ribeiro, J., Abbott, J. H., \& Jensen, M. P. (2019). Does religiosity/spirituality play a role in function, pain-related beliefs, and coping in patients with chronic pain? A systematic review. Journal of Religion and Health. https://doi.org/10.1007/s10943-019-00914-7
Fileborn, B., Brown, G., Lyons, A., Hinchliff, S., Heywood, W., Minichiello, V., Malta, S., Barrett, C., \& Crameri, P. (2018). Safer sex in later life: Qualitative interviews with older Australians on their understandings and practices of safer sex. Journal of Sex Research, 55(2), 164-177. https://doi.org/10.1080/00224499.2017.1280121.

Fischer, N., Træen, B., \& Hald, G. M. (2021). Predicting partnered sexual activity among older adults in four European countries: The role of attitudes, health, and relationship factors. Sexual and Relationship Therapy, 36, 3-21. https://doi.org/10.1080/14681 994.2018.1468560.

Foley, S. (2015). Older adults and sexual health: A review of current literature. Current Sexual Health Reports, 7, 70-79. https://doi. org/10.1007/s11930-015-0046-x.

Freak-Poli, R., Kirkman, M., Lima, G. C., Direk, N., Franco, O. H., \& Tiemeier, H. (2017). Sexual activity and physical tenderness in older adults: Cross-sectional prevalence and associated characteristics. Journal of Sexual Medicine, 14(7), 918-927. https://doi. org/10.1016/j.jsxm.2017.05.010.

Freak-Poli, R., Lichera, S., Ryanb, J., Ikrama, M. A., \& Tiemeier, H. (2018). Cognitive impairment, sexual activity and physical tenderness in community-dwelling older adults: A cross-sectional exploration. Gerontology, 64(6), 589-602. https://doi.org/10.1159/ 000490560 .

Golub, S. A., Botsko, M., Gamarel, K. E., Parsons, J. T., Brennan, M., \& Karpiak, S. E. (2011). Dimensions of psychological wellbeing predict consistent condom use among older adults living with HIV. Ageing International, 38, 179-194. https://doi.org/10. 1007/s12126-011-9126-z.

Graf, A. S., \& Patrick, J. H. (2014). The influence of sexual attitudes on mid- to late-life sexual well-being: Age, not gender, as a salient factor. International Journal of Aging and Human Development, 79(1), 55-79. https://doi.org/10.2190/AG.79.1.c.

Hillman, J. (2012). Sexuality and aging: Clinical perspectives (1st ed.). Springer.

Hinchliff, S., Tetley, J., Lee, D., \& Nazroo, J. (2017). Older adults' experiences of sexual difficulties: Qualitative findings from the English Longitudinal Study on Ageing (ELSA). Journal of Sex Research, 55(2), 152-163. https://doi.org/10.1080/00224499.2016.1269308.

Katz, S. (2010). Sociocultural perspectives on ageing bodies. In D. Dannefer \& C. Phillipson (Eds.), The SAGE handbook of social gerontology (pp. 357-366). Sage.

Kleinstäuber, M. (2017). Factors associated with sexual health and wellbeing in older adulthood. Current Opinion in Psychiatry, 30(5), 358-368. https://doi.org/10.1097/yco.0000000000000354.

Laumann, E. O., Paik, A., Glasser, D. B., Kang, J. H., Wang, T., Levinson, B., \& Gingell, C. (2006). A cross-national study of subjective sexual well-being among older women and men: Findings from the Global Study of Sexual Attitudes and Behaviors. Archives of Sexual Behavior, 35(2), 143-159. https://doi.org/10. 1007/s10508-005-9005-3.

Lindau, S. T., \& Gavrilova, N. (2010). Sex, health, and years of sexually active life gained due to good health: Evidence from two US population based cross sectional surveys of ageing. British Medical Journal, 340, c810. https://doi.org/10.1136/bmj.c810.

Mahieu, L., \& Gastmans, C. (2015). Older residents' perspectives on aged sexuality in institutionalized elderly care: A systematic literature review. International Journal of Nursing Studies, 52(12), 1891-1905. https://doi.org/10.1016/j.ijnurstu.2015.07.007.

Mendoza-Ruvalcaba, N. M., \& Fernández-Ballesteros, R. (2016). Effectiveness of the vital aging program to promote active aging in Mexican older adults. Clinical Interventions in Aging, 11, 1631-1644. https://doi.org/10.2147/cia.s102930.

Merz, E. M., Consedine, N. S., Schulze, H.-J., \& Schuengel, C. (2009). Wellbeing of adult children and ageing parents is associated with intergenerational support and relationship quality. Ageing and 
Society, 29(5), 783-802. https://doi.org/10.1017/S0144686X0 9008514.

Merz, E. M., \& Huxhold, O. (2010). Wellbeing depends on social relationship characteristics: Comparing different types and providers of support to older adults. Ageing and Society, 30, 843-857. https:// doi.org/10.1017/s0144686x10000061.

Minichiello, V., Rahman, S., Hawkes, G., \& Pitts, M. (2012). STI epidemiology in the global older population: Emerging challenges. Perspectives in Public Health, 132(4), 178-181. https://doi.org/ 10.1177/1757913912445688.

Mitchell, K. R., Mercer, C. H., Ploubidis, G. B., Jones, K. G., Datta, J., Field, N., \& Wellings, K. (2013). Sexual function in Britain: Findings from the third National Survey of Sexual Attitudes and Lifestyles (Natsal-3). The Lancet, 382(9907), 1817-1829. https:// doi.org/10.1016/S0140-6736(13)62366-1.

Neuendorf, K. (2002). The content analysis guidebook. (1st ed.). Sage.

Neuman, W. L. (2011). Social research methods: Qualitative and quantitative approaches (7th ed.). Pearson Education Inc.

Pearce, G., Thøgersen-Ntoumani, C., \& Duda, J. (2013). Body image during the menopausal transition: A systematic scoping review. Health Psychology Review, 8(4), 473-489. https://doi.org/10.1080/ 17437199.2013.848408.

Peixoto, M. M., \& Nobre, P. (2015). Prevalence and sociodemographic predictors of sexual problems in Portugal: A population-based study with women aged 18 to 79 years. Journal of Sex and Marital Therapy, 41(2), 169-180. https://doi.org/10.1080/0092623x. 2013.842195.

Pinquart, M., \& Sörensen, S. (2001). Gender differences in self-concept and psychological well-being in old age: A meta-analysis. Journal of Gerontology, 56(4), 195-213.

Raguso, C. A., Kyle, U., Kossovsky, M. P., Roynette, C., Paoloni-Giacobino, A., Hans, D., \& Pichard, C. (2006). A 3-year longitudinal study on body composition changes in the elderly: Role of physical exercise. Clinical Nutrition, 25(4), 573-580. https://doi.org/10. 1016/j.clnu.2005.10.013.

Reinhardt, J. P., Boerner, K., \& Horowitz, A. (2006). Good to have but not to use: Differential impact of perceived and received support on well-being. Journal of Social and Personal Relationships, 23(1), 117-129. https://doi.org/10.1177/0265407506060182.

Rheaume, C., \& Mitty, E. (2008). Sexuality and intimacy in older adults. Geriatric Nursing, 29(5), 342-349. https://doi.org/10.1016/j.gerin urse.2008.08.004.

Ribeiro-Gonçalves, J. A., Pereira, H., Costa, P. A., Leal, I., \& de Vries, B. (2021). Loneliness, social support, and adjustment to aging in older Portuguese gay men. Sexuality Research and Social Policy. https://doi.org/10.1007/s13178-021-00535-4.

Rosen, R. C., \& Bachmann, G. A. (2008). Sexual well-being, happiness, and satisfaction, in women: The case for a new conceptual paradigm. Journal of Sex and Marital Therapy, 34, 291-307. https:// doi.org/10.1080/00926230802096283.

Sampaio, R., \& Lycarião, D. (2018). Eu quero acreditar! Da importância, formas de uso e limites dos testes de confiabilidade na Análise de Conteúdo [I want to believe! About importance, ways of use, and limits of reliability tests in content analysis]. Revista de Sociologia e Política, 26, 31-47. https://doi.org/10. 1590/1678-987318266602.

Santos-Amaya, P. V., \& Carmona-Valdés, S. E. (2016). Genealogía socio-histórica del erotismo en adultos mayores. Revista Latinoamericana de Estudios sobre Cuerpos, Emociones y Sociedad, $19,8-19$

Santos-Iglesias, P., Byers, E. S., \& Moglia, R. (2016). Sexual wellbeing of older men and women. Canadian Journal of Human Sexuality, 25(2), 86-98. https://doi.org/10.3138/cjhs.252-a4.

Schaller, S., Traeen, B., Kvalem, L. I., \& Hinchliff, S. (2018). Linking the past and the present: Constructing meaning from childhood emotional and sexual experiences towards present sexual well-being in older adults. Sexual and Relationship Therapy, 35(3), 382-399. https://doi.org/10.1080/14681994.2018.15392 27.

Singh, K. (2007). Quantitative social research methods (1st ed.). Sage.

Sinković, M., \& Towler, L. (2018). Sexual aging: A systematic review of qualitative research on the sexuality and sexual health of older adults. Qualitative Health Research, 29, 1239-1254. https://doi. org/10.1177/1049732318819834.

Smith, L., Grabovac, I., Yang, L., Veronese, N., Koyanagi, A., \& Jackson, S. E. (2019). Participation in physical activity is associated with sexual activity in older English adults. International Journal of Environmental Research and Public Health, 16(3), 489-503. https://doi.org/10.3390/ijerph16030489.

Štulhofer, A., Jurin, T., Graham, C., Enzlin, P., \& Træen, B. (2019). Sexual well-being in older men and women: Construction and validation of a multi-dimensional measure in four European countries. Journal of Happiness Studies, 20, 2329-2350. https://doi.org/10. 1007/s10902-018-0049-1.

Štulhofer, A., Jurin, T., Graham, C., Janssen, E., \& Træen, B. (2020). Emotional intimacy and sexual well-being in aging European couples: A cross-cultural mediation analysis. European Journal of Ageing, 17, 43-54. https://doi.org/10.1007/s10433-019-00509-x.

Syme, M. L., Cohn, T. J., Stoffregen, S., Kaempfe, H., \& Schippers, D. (2018). "At my age...": Defining sexual wellness in mid- and later life. Journal of Sex Research, 56(7), 332-342. https://doi.org/10. 1080/00224499.2018.1456510.

Torres, S., \& Rodríguez-Martín, B. (2019). Perceptions of sexuality in older people: A systematic review of qualitative studies. Revista Española de Salud Pública, 93(4), 1-17.

Træen, B., Carvalheira, A. A., Hald, G. M., Lange, T., \& Kvalem, I. L. (2019). Attitudes towards sexuality in older men and women across Europe: Similarities, differences, and associations with their sex lives. Sexuality and Culture, 23, 1-25. https://doi.org/10.1007/ s12119-018-9564-9.

Træen, B., Carvalheira, A., Kvalem, I. L., Štulhofer, A., Janssen, E., Graham, C. A., \& Enzlin, P. (2017a). Sexuality in older adults $(65+)$-An overview of the recent literature, Part 2: Body image and sexual satisfaction. International Journal of Sexual Health, 29(1), 11-21. https://doi.org/10.1080/19317611.2016.1227012.

Træen, B., Hald, G. M., Graham, C. A., Enzlin, P., Janssen, E., Kvalem, I. L., \& Štulhofer, A. (2017b). Sexuality in older adults (65+)—An overview of the literature, Part 1: Sexual function and its difficulties. International Journal of Sexual Health, 29(1), 1-10. https:// doi.org/10.1080/19317611.2016.1224286.

Træen, B., \& Villar, F. (2020). Sexual well-being is part of aging well. European Journal of Ageing, 17(2), 135-138. https://doi.org/10. 1007/s10433-020-00551-0.

United Nations (UN). (2015). World population prospects: The 2015 revision, key findings and advance tables. Author.

Unsar, S., Erol, O., \& Sut, N. (2016). Social support and quality of life among older adults. International Journal of Caring Sciences, 9, 249-257.

Vala, J. (1989). A análise de conteúdo [The content analysis]. In A. S. Silva \& J. M. Pinto (Eds.), Metodologia das ciências sociais (pp. 101-128). Afrontamento.

von Humboldt, S., \& Leal, I. (2014a). Adjustment to aging in old adulthood: A systematic review. International Journal of Gerontology, 8(5), 108-113. https://doi.org/10.1016/j.ijge.2014.03.003

von Humboldt, S., \& Leal, I. (2014b). ¿Qué influye en el bienestar subjetivo de los adultos mayores?: Una revision sistematica de la literature [What influences older adults' subjective well-being?: A systematic review]. Revista Argentina de Clínica Psicológica, $23,219-230$.

von Humboldt, S., \& Leal, I. (2015). The old and the oldest old: Do they have different perspectives on adjustment to aging? International 
Journal of Gerontology, 9(3), 156-160. https://doi.org/10.1016/j. ijge.2015.04.002

von Humboldt, S., Leal, I., Laneiro, T., \& Tavares, P. (2013a). Examining occupational stress, sources of stress and stress management strategies through the eyes of consultants: A multiple correspondence analysis for latent constructs. Stress \& Health, 29, 410-420. https://doi.org/10.1002/smi.2487

von Humboldt, S., Leal, I., \& Pimenta, F. (2013b). Analyzing adjustment to aging and subjective age from Angolan and Portuguese community-dwelling older adults' perspectives. International Journal of Gerontology, 27(4), 209-215. https://doi.org/10.1016/j. ijge.2013.05.001

von Humboldt, S., Leal, I., \& Pimenta, F. (2014a). Living well in later life: The influence of sense of coherence, and socio-demographic, lifestyle and health-related factors on older adults' satisfaction with life. Applied Research in Quality of Life, 9, 631-642. https://doi. org/10.1007/s11482-013-9262-6

von Humboldt, S., Leal, I., \& Pimenta, F. (2014b). Does spirituality really matter? A study on the potential of spirituality to older adult's adjustment to aging. Japanese Psychological Research, 56, 114-125. https://doi.org/10.1111/jpr.12033

von Humboldt, S., Leal, I., \& Pimenta, F. (2015). Sense of coherence, sociodemographic, lifestyle, and health-related factors in older adults' subjective well-being. International Journal of Gerontology, 9(1), 15-19. https://doi.org/10.1016/j.ijge.2014.01.007

von Humboldt, S., Low, L., \& Leal, I. (2020). Are older adults satisfied with their sexuality? Outcomes from a cross-cultural study.
Educational Gerontology, 46(5), 284-293. https://doi.org/10. 1080/03601277.2020.1744805.

von Humboldt, S., Monteiro, A., \& Leal, I. (2018). How do older adults experience intergenerational relationships? Different cultures, ambivalent feelings. Educational Gerontology, 44(8), 501-513. https://doi.org/10.1080/03601277.2018.1520528.

von Humboldt, S., Ribeiro-Gonçalves, J. A., Costa, A., Low, G., \& Leal, I. (2021). Sexual expression in old age: How older adults from different cultures express sexually? Sexuality Research and Social Policy, 18, 246-260. https://doi.org/10.1007/s13178-020-00453-x.

Watson, W. K., Stelle, C., \& Bell, N. (2016). Older women in new romantic relationships. International Journal of Aging and Human Development, 85, 33-43. https://doi.org/10.1177/0091415016 680067.

World Health Organization (WHO). (2010). Measuring sexual health: Conceptual and practical considerations and related indicators. Author.

World Health Organization (WHO). (2015). World report on ageing and health. Author.

Publisher's Note Springer Nature remains neutral with regard to jurisdictional claims in published maps and institutional affiliations. 